\title{
The Effect of Situated Learning on Students' Vocational English Learning
}

\author{
Melike Özüdoğrư ${ }^{1}$, Fatma Özüdoğrü,** \\ ${ }^{1}$ Department of Educational Sciences, Manisa Celal Bayar University, Turkey \\ ${ }^{2}$ School of Foreign Languages, Usak University, Turkey
}

Copyright $\mathrm{O} 2017$ by authors, all rights reserved. Authors agree that this article remains permanently open access under the terms of the Creative Commons Attribution License 4.0 International License

\begin{abstract}
The current study aimed to find out the effect of situated learning on students' Vocational English learning. This research employed a mixed method research design. In the quantitative part of the study, pre-tests and post-tests were implemented to investigate the differences in students' vocational English learning between the experimental and the control group. Besides, the qualitative part of the research consisted of semi-structured interviews in order to explore students' perceptions about situated learning. This study involved 116 second grade students who were studying in the department of Accounting Information Systems. The data were gathered through an achievement test, developed by the researchers, and semi-structured interviews. A paired samples t-test and independent samples t-test were employed in order to analyze the quantitative data. Furthermore, descriptive analysis was carried out to analyze the qualitative data. According to the findings of the study, the average score of the achievement test for control group was found to be lower than the experimental group; however, a significant difference was not obtained. It was also unearthed that the perceptions of students about situated learning were mostly positive. Thus, it can be concluded that situated learning can be used successfully in teaching students vocational English.
\end{abstract}

Keywords Situated Learning, Vocational English, Accounting

\section{Introduction}

Formal education treats knowledge as a self-sufficient, and decontextualized of the situations in which it is learned and used. The main purpose of schools is to transfer the theoretical knowledge which includes mostly abstract and formal concepts [24]. However, in this information era, many researchers have discussed the separation of what is learned from how it is learned and used [1] because experts and practitioners in real life treat and use skills and knowledge very differently from formal education settings
[16]. Hence, many students come across with problems in practicing the knowledge and skills learned through formal learning to their daily lives and work places [16]. Rather than the knowledge that is memorized, tested and then forgotten, the knowledge used by learners outside the schools is more valuable. The instruction which is given in meaningful, contextualized learning environments may be more understandable and applicable in authentic situations [22]. Hence, Situated Learning or Situated Cognition was expounded by [24] who claimed that knowledge was linked to the activity, context, and culture in which it was learned.

The critical characteristics of situated learning environments have been defined in previous studies $[12,18$, 20, 26]. For example, Herrington \& Oliver [18] defined nine characteristics of situated learning environments for the design of instruction as (1) authentic contexts, (2) authentic activities, (3) access to expert performances, (4) multiple roles and perspectives, (5) collaborations, (6) reflections, (7) diverse opportunities, (8) coaching and scaffoldings and (9) authentic assessment.

Firstly, in the instruction designed according to the principles of situated learning, authentic contexts reflecting the real world in which the knowledge is used, authentic activities which have real world relevance and require students' active participation should be provided. According to McLellan [14], "authentic contexts can be a/an 1) actual work setting 2) virtual representation of the actual work environment 3) anchoring contexts such as a video or multimedia program" (p. 8). However, there are conflicting opinions in the literature as to which contexts and activities are accepted as authentic. According to Hummel [13], "the implementation of situated learning theory by electronic media take an important step away from this theory since courseware becomes the learning environment and not the authentic situation" (p. 15). On the other hand, lots of researchers $[24,28,30]$ asserted that computers can provide an alternative to the real-life setting and that such technology can be used without sacrificing the authentic context. Reeves [30] indicated interactive multimedia environments include opportunities for simulated apprenticeships and different 
kinds of learning support activities. Collins (1988) stated that computers create situated learning environments that reflect reading, writing, mathematics, science and social studies in ways students learn in real life [cited in 20].

Also, in a situated learning environment students should be catered for access to expert performance and modeling or observation of real-life events as they occur together with multiple roles and perspectives that each student expresses different points of views. In situated learning environments, students have the opportunity to observe an activity or task before it is applied in real context, which is named as access to expert performances and the modeling of processes by Brown et al. [24]. For example, short movies of experts performing skills such as a teacher asking open or closed ended questions, or applying different classroom management strategies, a psychologist counselling a client, a building adviser assessing foundations, or a farmer judging the quality of a product allow students the opportunity to observe the experienced practitioners at work [24].

In addition, learners should be supplied with collaborative activities which support collaborative construction of knowledge and higher-order thinking skills as well as reflection processes that enable abstractions, and diverse opportunities to articulate, negotiate, and defend their knowledge [20]. Herrington et al. [21] stated that a successful teaching-learning process provides activities that direct students to define their own problems and solve them in collaborative interpersonal activities. Moreover, for successful learning, activities should be designed to require time over a period of days, weeks or months, rather than short time. In addition, authentic activities should be integrated into different subject areas and should allow for collaboration, reflection and multiple solutions [4]. Furthermore, instructors need to provide coaching and scaffolding in time to help students generate their knowledge in complex contexts, and integrate different tasks that make them effective performers and assess them in realistic environments and contexts.

While the theoretical literature about situated learning is abundant $[18,19,20,24,27,29]$, the situated learning method lacks substantive empirical support. Situated learning has been applied to language learning [2, 7, 31, 32], distance education library research course [1], educational technology course [25], the school principalship: seminars and simulations graduate course [11], and instructional strategies for students with special needs [5].

Various characteristics of situated learning environments were taken into account in various domains. In the study conducted by Huang et al. [21], a situated learning environment was created for an educational technology course. In this study, the authentic context was "parent-teacher" interview and students prepared all the materials needed for the parent-teacher conference as an authentic task, which required problem solving skills. Project artifacts were used as authentic assessments. The authentic context provided students with autonomy to make decisions about what software and skills to use. Comas-Quinn et al. [2] developed a webpage and blog for the situated learning environment. Students used a webpage and blog as an interactive repository to share examples of their cultural encounters with the location. Students took photos and prepared videos related to a foreign culture with their mobile devices and uploaded them to the cultural blog.

In the study of Pan [11], a situated learning environment was designed for school principals and they were provided with simulation materials and digital videos. The course consisted of class discussion seminars, simulation sessions in the computer lab, readings, and journal writing that enabled the students to reflect on their performance as school administrators. These computer-based instructional simulations substituted the experience of field practice.

The previous studies reported that situated learning helped to promote pre-service math teachers' higher-order thinking skills [19], indicated its potential to facilitate transfer to real world contexts [1], students had positive perceptions about situated learning environment [8], students demonstrated sophisticated problem-solving skills, exhibited metacognitive awareness, produced coherent artifacts, and high levels of motivation $[6,25]$ and promoted long-term retention, contextual and incidental learning of vocabulary [7], enhanced emotional and cognitive engagement [11].

Although various characteristics of situated learning environments in different subject areas were studied, there exists little research about language learning. Oura [10] emphasized the importance of attracting the attention of students by using different teaching methods so that they could learn English and use it in their daily lives, which is an important challenge that language teachers frequently face. For example, as stated by Uz-Bilgin [7], students complain about the fact that they forget the meaning of the words quickly and have difficulty in memorizing words which indicate that students generally do not know how to learn vocabulary and English in general. Hence, many teachers in different education levels adapt different activities involving authentic materials or media.

Nunan (1999) defines authentic materials for language learning as the materials that are not specifically written for purposes of language teaching but as spoken or written language data that have been produced in the course of communication [cited in 10]. For example, students practice listening and reading language drawn from various media, including movies, magazine stories, songs, talk shows, advertisements, radio broadcasts, e-mails, hotel brochures, and announcements [15], which offer students a valuable source of language input so that they are not being exposed to the language presented only by texts or teachers [10].

Although critical features of situated learning, which were indicated previously, were involved in different studies, there is little known about the effectiveness of situated learning on students' learning. While some studies indicated that situated learning increased student achievement [9], other studies did not indicate a significant difference [7]. 
Therefore, an investigation is needed to determine whether situated learning results in different effects with respect to students' knowledge acquisition. Moreover, studies investigating the impact of situated learning on students' vocational English learning are relatively few.

The aim of this study was to identify whether there was a significant difference between the achievement scores of students who were instructed according to traditional and situated learning principles. In this study, students who study in the department of Accounting Information Systems and take "Vocational English II" course do not have the opportunity to learn vocational English vocabulary in real-life communication. Hence, they use memorization strategies, which enable slow and less successful learning. In this respect, this study employed situated learning environments which provided authentic learning opportunities.

\section{The Purpose and Significance of the Study}

The current study aimed to find out the effect of situated learning on students' Vocational English learning. Furthermore, this study aimed to discover students' perceptions about the activities based on situated learning. In order to achieve the main purpose of the study, the following research questions were posed:

1. Is there a significant difference between pre-test and post-test English achievement scores of students who were exposed to traditional instruction?

2. Is there a significant difference between pre-test and post-test English achievement scores of students who were exposed to instruction based on situated learning principles?

3. Is there a significant difference between post-test scores of students who were exposed to traditional instruction and situated learning principles?

4. What are the perceptions of students about instruction based on the principles of situated learning?

This study is one of the experimental studies conducted in Turkey, examining the efficacy of situated learning environments on students' vocational English learning. Additionally, this study included situated learning approach by incorporating different characteristics of situated learning as authentic activities, expert modeling, instructor feedback, collaborative activities, peer feedback, in different contexts and with different materials. Finally, the present study, different from previous studies, included out-class authentic activities which were parallel to in-class activities.

\section{Materials and Methods}

\subsection{Research Design}

This research employed a mixed method research design combining both quantitative and qualitative method. Since the purpose of the quantitative part of the research was to investigate the differences in students' vocational English learning between the experimental and the control group, pre-tests and post-tests were implemented. Besides, the qualitative part of the research consisted of semi-structured interviews with students in the experimental group in order to explore students' perceptions about the effect of situated learning on learning vocational English.

\subsection{Participants}

This study involved a sample of 116 students who were studying in the second grade of Accounting Information Systems department in the School of Applied Sciences at a state university located in the West part of Turkey and enrolled in Vocational English II, a three-credit course. In accordance with the purpose and design of this study, experimental and control groups were formed. Two sections of this course were randomly assigned as the experimental and control group. In order to determine whether the two groups were equivalent in terms of academic achievement, the achievement test was implemented as pre-test at the beginning of the treatment. The pre-test mean score of students in the control group is $X=19.99$ and the mean score of students in the experimental group is $X=20.26$. In order to compare the groups, independent samples t-test was implemented and a significant difference between the groups was not obtained ( $p>.05)$. Hence, it can be said that both groups were equivalent at the beginning of the experiment.

\subsection{Learning Environments}

Students studying in Accounting Information Systems department take four Vocational English courses, in the second and third grade in both semesters. Students have been taught via traditional methods so far such as reading accounting-related texts and translating. Hence, students in the control group received instruction through traditional methods. They used a course book and read texts related to accounting and translated it into Turkish, then they answered reading comprehension questions and did fill in the blanks vocabulary exercises. However, students in the experimental group received instruction based upon the principles of situated learning. Students were presented with realistic situations that they might encounter in the real world. In the first week, students watched a video about balance sheets in class, through which the instructor presented the target vocabulary. Then, the students were asked to think about a problem that may occur in a balance sheet and then come up with solutions. Students discussed it in class in groups and then were asked to prepare a video discussing the problem and possible solutions outside the class. Students prepared videos and then shared them in their class whatsapp group until next week. Students gave feedback to other groups' videos and the instructor provided 
instructional support when necessary. In the second week, the instructor showed a sample cash flow statement to the students and they analyzed parts of it in groups. Then, students were asked to act as an accountant and write a response e-mail to the manager in groups about complicated numbers on the income statement and the cash flow statement.

In the third week, the instructor showed a weekly sales report of a well-known shop located where they live and they talked about the rise and decrease in the sales report day by day, through which the instructor presented the target vocabulary. Students were then asked to receive the weekly sales report of different companies, talk to the manager about the report and record it as a video. Later, students shared videos and reports in class and talked about the increase or decline in sales, which an accountant does in real-life. In the fourth week, students were asked to bring different financial statements which they could find through internet or magazines. The instructor gave some financial formulas such as return on sales and return on equity. Then, students were asked to find out the ratios in the financial statements by using the formulas and then discuss the results in groups.

Thus, the curriculum represents a situated learning approach by incorporating authentic activities, expert modeling, scaffolding, instructor feedback, peer feedback and learning in different contexts and with different materials (videos, reports, internet sources).

\subsection{Data Collection}

This study lasted four weeks. The data were gathered in the spring semester of 2016-2017 academic years through an achievement test and semi-structured interviews. The target vocabulary for the achievement test was determined and the test was developed by the second researcher of this study who was teaching this course and another colleague who had taught this course before. Having prepared the draft test, expert opinion was taken from two English field experts. The final test included 32 multiple choice questions testing 50 target vocabulary from the four units studied during four weeks. Topics covered in four weeks include balance sheets, cash flow statements, describing change in sales report and gleaning information from financial statements. The target vocabulary were determined as "balance sheet, asset, liability, equity, own, owe, cash, inventory, accounts receivable, accounts payable, fixed assets, debt, sum, value, cash flow statement, inflow, outflow, cash distribution, dividends, stockholder, payment, generate, cumulative cash, proceeds, slightly, plummet, sharply, stabilize, steadily, recover, decline, rise, increase, go up, go down, fall, decrease, stable, unchanged, fluctuate, skyrocket, hover, assess, interpret, year-over-year growth rate, return on sales, return on equity, uncollectible, eat away at, keep record." The achievement test was administered both as pre-test and post-test.
Moreover, semi-structured interviews were administered to seven willing students in the experimental group at the end of the treatment to find out their perceptions about the activities and applications based upon situated learning. Four questions were prepared within the framework of situated learning activities. The draft interview form was presented to the views of two educational sciences expert for content validity. After feedback was received, the form was finalized by removing similar questions. Each interview lasted about 15-20 minutes and was conducted in Turkish to make students feel more comfortable in conveying their views and recorded for transcription. The interview questions are listed as:

1. How can you state the new method conducted in the last four weeks with one word or sentence?

2. What are your opinions about the first weeks of this course and activities and applications carried out in the last four weeks?

3. What do you think about the strengths and weaknesses of the activities and applications carried out in the last four weeks?

4. Do you prefer such activities and applications to be used in the next Vocational English courses? Why or why not?

\subsection{Data Analysis}

Statistical Package for the Social Sciences (SPSS) version 22 was used to analyze the quantitative data. In order to make comparisons between the groups non-parametric tests need to be used when the sample size is less than 30 , and parametric tests are required to be used when the sample size is more than 30 [17, 23]. Therefore, a "Paired samples t-test" was used in order to compare the achievement pre-test and post-test mean scores within the experimental and control groups (sample $>30$ ) and an "Independent samples t-test" was used for the comparison of achievement pre-test and post-test results between the experimental and control groups (sample $>30$ ). Furthermore, descriptive analysis was carried out to find out the perceptions of students in the experimental group about the instruction based on the principles of situated learning. For descriptive analysis, the framework offered by Yıldırım \& Şimşek [3] was followed. Hence, an analysis form consisting of the themes to be analyzed was prepared. Each theme was given a code and the data were analyzed in accordance with the thematic form and then findings were interpreted.

\section{Results}

In this section, data analysis of the results related to the four research questions is provided. 
Table 1. Mean and standard deviation for the achievement scores of the control group

\begin{tabular}{|c|c|c|c|}
\hline & $M$ & $S D$ & $N$ \\
\hline Pre-test & 19.99 & 6.49 & 58 \\
\hline Post-test & 28.29 & 14.04 & 58 \\
\hline
\end{tabular}

As it was indicated in Table 1, post-test mean score $(\mathrm{M}=$ 28.29, SD =14.04) of students in the control group were higher than their pre-test mean score $(\mathrm{M}=19.99, \mathrm{SD}=6.49)$. The mean differences between pre-test and post-test of the control group are shown in Table 2.

Table 2. Mean differences between pre-test - post-test of the control group

\begin{tabular}{|c|c|c|c|c|c|}
\hline & $\mathrm{M}$ & $\mathrm{SD}$ & $\mathrm{SE}$ & $\mathrm{t}$ & $\mathrm{Df}$ \\
\hline $\begin{array}{c}\text { Pre-test } \\
\text { Post-test }\end{array}$ & -8.30 & 14.25 & 1.87 & -4.43 & 57 \\
\hline
\end{tabular}

$* \mathrm{p}<.000$

As it was unearthed in Table 2, students' post-test scores were significantly higher than their pre-test scores, $\mathrm{t}(58)=$ $-4.43, p<.05$. Overall results indicated that there was an improvement in the control group between the pre-test and post-test scores. The pre-test and post-test mean score and standard deviation of students in the experimental group were presented in Table 3.

Table 3. Mean and standard deviation for the achievement scores of the experimental group

\begin{tabular}{|c|c|c|c|}
\hline & M & SD & N \\
\hline Pre-test & 20.26 & 8.76 & 58 \\
\hline Post-test & 32.02 & 13.81 & 58 \\
\hline
\end{tabular}

As it can be seen from Table 3, the post-test mean score $(\mathrm{M}=32.02, \mathrm{SD}=13.81)$ of students in the experimental group were higher than their pre-test mean score $(\mathrm{M}=20.26$, $\mathrm{SD}=8.76)$. The mean differences between pre-test and post-test of the control group are shown in Table 4.

Table 4. Mean differences between pre-test - post-test of the experimental group

\begin{tabular}{|c|c|c|c|c|}
\hline & $M$ & $S D$ & $t$ & $d f$ \\
\hline $\begin{array}{c}\text { Pre-test } \\
\text { Post-test }\end{array}$ & -11.76 & 16.66 & -5.37 & 57 \\
\hline
\end{tabular}

$* \mathrm{p}<.000$

Data in Table 4 indicated that the post-test mean score of students in the experimental group was significantly higher than their pre-test mean score, $\mathrm{t}(58)=-5.37, \mathrm{p}<.05$. Overall results indicated that there was an improvement in the experimental group between pre-test and post-test scores.

In order to answer the third research question whose purpose is to investigate whether there was a significant difference between post-test scores of students who were in experimental and control groups, independent samples t-test was conducted and the results were indicated in Table 5.
Table 5. Post-test scores of the experimental and control group

\begin{tabular}{|c|c|c|c|c|c|}
\hline & $\mathrm{M}$ & $\mathrm{SD}$ & $\mathrm{t}$ & $\mathrm{df}$ & $\mathrm{P}$ \\
\hline Exp. Gr. & 32.02 & 13.82 & \multirow{2}{*}{1.44} & \multirow{2}{*}{114} & .15 \\
\hline Cont. Gr. & 28.29 & 14.04 & & & \\
\hline
\end{tabular}

$* \mathrm{p}>.05$

As revealed in Table 5, the post-test mean score of experimental group was higher than that of the control group; however, this result showed no statistically significant difference $(t=1.44, p>.05)$. Hence, it can be stated that the vocational English achievement of students did not differ significantly.

Finally, in order to answer the fourth research question, the data obtained from the semi-structured interviews were analyzed and categorized into nine themes. The themes are 'authentic context', 'authentic activities', 'expert performance, coaching and scaffolding', 'multiple perspectives', 'collaboration', 'reflection', 'authentic assessment', 'positive sides of situated learning' and 'negative sides of situated learning'.

\section{Authentic Context}

The results indicated that students were satisfied with the learning environment generated through situated learning. Some of the sample responses were indicated below:

"Learning Environment facilitated learning, it was fun, it enhanced communication with the instructor." (S2)

"It was fun and enabled effective learning with materials" (S6)

\section{Authentic Activities}

Students stated that they were more active in situated learning contexts. Students were assigned authentic tasks which were similar to real world situations. Since they had opportunity to apply the topics learned in class to real life events often, they could retain more information about English. Some of the sample responses were indicated below:

"In the first weeks, the lessons were very monotonous, but after the new applications, I can say that the whole situation changed. Thanks to video works, we were more active in the lesson. In this way, we had the opportunity to revise what we have learned." (S2)

I was more active because in the previous lessons I did not revise the topics until the exams, hence I forgot. However, after preparing video based assignments, we learned more and the subjects became more permanent."(S3)

\section{Expert Performance, Coaching and Scaffolding}

According to the perceptions of students, the instructor helped students observe their performance and use the new knowledge as a model in their own tasks and activities. 
"The instructor taught the pronunciation of words related to vocational English, corrected our mistakes and helped us choose the correct vocabulary and make accurate sentences, later we used this knowledge in our videos..." (S7)

\section{Multiple Perspectives}

Students believed that although assignments were very challenging, it facilitated learning more because of involving different tasks. Hence, students did not get bored and worked on different parts of the vocational English topics.

"The video tasks were very challenging, but it facilitated learning a lot because we used both visual and audial methods. For example, we watched videos, we prepared videos with our peers, we worked on a balance sheet and we wrote e-mail to accountants" (S4)

\section{Collaboration}

Cooperative participation was seen as one of the most important characteristics of situated learning by students because they shared their ideas and in this way they could learn from each other.

"The video assignments and tasks provided us to work in groups and collaborate." (S1)

"We spent more time as a group and came up with better products. "(S6)

\section{Reflection}

According to the perceptions of students, they learned to analyze their own work and compare it with the work of their peers. One of the students stated that "This method should be used in the next semester because thanks to this method I am aware of the fact that I can learn vocational English."

\section{Authentic Assessment}

Students stated that instead of traditional evaluation methods, they liked authentic assessment because it focused on evaluating students' understanding and problem solving.

"The instructor gave feedback about our performance and corrected our pronunciation mistakes and helped us choose the correct vocabulary and make accurate sentences"(S1)

\section{Positive Sides}

It was stated by students that they were mostly satisfied with situated learning. Most of the students perceived that the activities and applications of situated learning were beneficial and that their communication and pronunciation improved, they learned better and their motivation increased.

"The course assignments and tasks were very hard and challenging... but thanks to the difficulty of the assignments, we tried harder and learned English better." (S3)

"I was less interested in lessons before this method, but later the course drew my attention and so my final grade was very high while my midterm grade was low." (S1).

"Different tasks provided us to pronounce better, learn the meanings of words easier and do the assignments more willingly." (S2)

\section{Negative Sides}

Although students were mostly positive about situated learning, some students indicated some weaknesses of it. Some students perceived the assignments given for each week as time consuming and very challenging.

"The course assignments and tasks were very time consuming. I felt overloaded" (S4)

"Video is a very challenging method." (S1).

"These assignments should not be given every week, they should be given occasionally because students may get bored due to the overload." (S6)

\section{Conclusions and Discussion}

The aim of this study was to find out the effect of situated learning on students' Vocational English learning and explore students' perceptions about the activities based on situated learning. According to the results of this study, students in both experimental and control group indicated an improvement between the pre-test and post-test scores; however, a significant difference was not obtained between the post-test scores of each group. This result is similar to Uz-Bilgin's [7] study, in which an improvement in students' vocabulary learning was found though there was no significant difference between students' post-test and retention test scores. In contrast, in the study conducted by Huang et al. [21], it was revealed that in the final examination students in the situated environment performed poorer than the students instructed according to traditional instruction in knowledge acquisition and use of more advanced technologies. The reason for this can be explained as groups in situated environment split up their work among group members after initial planning, and although students communicated among group members, they mostly tended to work on their share without paying equal attention to the skill areas others were working with. As also emphasized by Huang et al. [21], students mostly stayed in their comfort zone and did not try to learn other parts of the work that needs to be completed by another group member while preparing projects or in the final examinations.

Another result of the present study indicated that students were satisfied with the learning environment and perceived the learning environment as a factor that facilitated learning and enhanced their engagement and communication with the instructor. This result is consistent with the study conducted by Pan [11] who indicated that students' engagement was enhanced in situated language learning 
environment. While students exhibited emotional engagement through expressing their thoughts and opinions about the drama in the discussions at e-meeting, they exhibited cognitive engagement by acquiring vocabulary knowledge and sentences with the help of scaffolding. Also, through asynchronous communication, students practiced engagement in writing essays about the drama.

In addition, it was revealed in the current study that although assignments were perceived very challenging, it facilitated learning more because of involving different tasks. Hence, students did not get bored and worked on different parts of the vocational English topics. In the present study, students practiced English by writing e-mails, preparing videos with their peers, working on a balance sheet and sales report. Providing students with the opportunity to practice the knowledge in different situations or contexts encouraged them to apply the knowledge to real-life situations as also stated by Catalano [1]. Although Huang et al. [25] indicated that transferring was not an easy process because of requiring higher cognitive skills, in this study students applied knowledge learned in class to out-class activities. Hence, by integrating in-class and out-class activities, misunderstandings were minimized. This result was consistent with the study of Yang [32] in which an online learning environment was created and students got engaged in both synchronous and asynchronous communication.

Examining the results of this study, it was unearthed that collaborative learning was one of the most important characteristics of situated learning because students shared their ideas and in this way they could learn from each other. The reason for this can be explained as group members' help which resulted in their learning much from each other and coming up with better products. Moreover, students mostly prefer learning from peers instead of instructor in both formal and informal learning contexts. Also, students learned to analyze their own work and to compare it with the work of their peers. Hence, they value learning from peers much. Supporting this result, in the study carried out by Utley [5], students at a teacher education course indicated cooperative learning theme as one of the criteria producing willingness on the part of class members to apply instructional strategies in their own practice.

Another result obtained from the present study was that students were mostly satisfied with the instruction based on situated learning principles. Most of the students perceived the applications of situated learning beneficial as well as fun. They indicated that their communication and pronunciation improved, they learned better and their motivation increased. Similar to this study, in the study conducted by Kim [15], it was disclosed that students found learning with videos enjoyable because several factors like students' motivation, interests and content of each week were considered while choosing video materials. Furthermore, in this study, it was ascertained that students were more engaged and active in the course because the instructor provided instant feedback and became a model in teaching vocational English.

According to the results of this study, it can be suggested that instructors should use a wide range of materials in class and suggest students to read books and magazines related to accounting, write e-mails, and watch advertisements and films in English to make connections between English learned in classes and the real world. In this study, students indicated the value of learning from peers as one of the important aspects of the course. Thus, cooperative learning based on the principles and practices of situated learning can be employed by instructors in class. In this respect, learners' processes in different learning environments such as mobile supported and virtual reality can be examined. Also, factors such as learner's motivation, anxiety, and learning styles can be explored by supporting with empirical findings in the future.

Finally, there were some limitations about the results of this study. One of the limitations of this study was its duration. Since it was hard to apply all of the characteristics of situated learning environment proposed by Herrington \& Oliver [18] through a short term intervention, the duration of the study could be extended by embedding different contexts to help students learn vocational English. Hence, as a further study, it can be suggested that longer studies should be conducted in order to investigate the effect of situated learning on students' achievement. Also, a similar study can be conducted in general English courses. Another limitation of this study was its small sample size which restricts making generalizations about its findings. That is, the results cannot be generalized to all settings where vocational English is instructed. Thus, it is strongly suggested that a further research in different courses with larger sample size and in different grade levels should be implemented.

\section{REFERENCES}

[1] A. Catalano. The effect of a situated learning environment in a distance education information literacy course, Journal of Academic Librarianship, 41(5): 653-659. https://doi.org/10.1016/j.acalib.2015.06.008, 2015.

[2] A. Comas-Quinn, R. Mardomingo, C. Valentine. Mobile blogs in language learning: Making the most of informal and situated learning opportunities, ReCALL, 21(01): 96-112, 2009.

[3] A. Yıldırım, H. Şimşek. Sosyal Bilimlerde Nitel Araştırma Yöntemleri, Seçkin Yayınc1lık, ISBN: 9789750239991, 2005.

[4] B. A. Lankard. New ways of learning in the workplace, 1995. Eric no: ED385778

[5] B. L. Utley. Effects of situated learning on knowledge gain of instructional strategies by students in a graduate level course," Teacher Education and Special Education, 29(1), 69-82, 2006. 
[6] C. S. J. Huang, S. J. H. Yang, T. H. C. Chiang, A. Y. S. Su. Effects of situated mobile learning approach on learning motivation and performance of EFL students, Journal of Educational Technology \& Society, 19(1): 263-276, 2016.

[7] C. Uz-Bilgin. Facilitating English as a Foreign Language Learners' Vocabulary Learning, Task Completion and Contextual Vocabulary Exploration Processes in A Mobile Supported Situated Learning Environment, Unpublished PhD Dissertation, Middle East Technical University, Ankara, Turkey, 2016.

[8] C. Ünal, H. Z. İnan. Students' perceptions of a situated learning environment, Procedia Social and Behavioral Sciences, 2, 2171-2175.

[9] F. N. Hossainy, H. Zare, M. Hormozi, F. Shaghaghi, M. H. Kaveh. Designing and implementing a situated learning program and determining its impact on the students' motivation and learning, Turkish Online Journal of Distance Education-TOJDE, 13(2): 36-47, 2012.

[10] G. K. Oura, Authentic task-based materials: Bringing the real world into the classroom, Sophia Junior College Faculty Bulletin, 21: 65-84, 2001.

[11] G. Pan. Situated Cognition in a Technology-Based Learning Environment, Unpublished $\mathrm{PhD}$ Dissertation, University of Alberta, Edmonton, USA, 2005.

[12] H. C. Chu, G. J. Hwang, C. C. Tsai, J. C. Tseng. A two-tier test approach to developing location-aware mobile learning systems for natural science courses," Computers \& Education, 55(4): 1618-1627, 2010.

[13] H. G. K. Hummel. Distance education and situated learning:Paradox or partnership, Educational Technology, 33(12): 11-22, 1993.

[14] H. McLellan. Situated learning: Continuing the conversation, Educational Technology, 34(10): 7-8, 1994.

[15] H. S. Kim. Using authentic videos to improve EFL students' listening comprehension, International Journal of Contents, 11(4): 15-24, 2015. doi: 10.5392/IJoC.2015.11.4.015

[16] J. Choi, M. Hannafin. Situated cognition and learning environments: Roles, structures, and implications for design, Educational Technology Research and Development, 43(2): 53-69, 1995.

[17] J. R. Fraenkel, N. E. Wallen, H. H. Hyun. How to Design and Evaluate Research in Education, McGraw Hill, ISBN: 978-0078097850, 2006.

[18] J. Herrington, R. Oliver. Critical Characteristics of Situated Learning: Implications for the Instructional Design of Multimedia, ASCILITE 1995 Conference, 3-7 December
1995, University of Melbourne, Melbourne, 1995.

[19] J. Herrington, R. Oliver. Using situated learning and multimedia to investigate higher-order thinking," Journal of Educational Multimedia and Hypermedia, 8(4): 401-421, 1999.

[20] J. Herrington, R. Oliver. An instructional design framework for authentic learning environments, Educational Technology Research \& Development, 48(3): 23-48, 2000.

[21] J. Herrington, T. C. Reeves, R. Oliver. Authentic tasks online: A synergy among learner, task, and technology, Distance Education, 27(2): 233-247, 2006.

[22] J. Kim. The Effect of Situated Learning on Knowledge Transfer of Students with and without Disabilities in Inclusive Classrooms," Unpublished PhD Dissertation, The University of Texas at Austin, USA, 2012.

[23] J. Pallant. SPSS Survival Manual," Australia: Allen \& Unwin, 2005.

[24] J. S. Brown, A. Collins, P. Duguid. Situated cognition and the culture of learning, Educational Researcher, 18: 32-42, 1989.

[25] K. Huang, I. A. Lubin, X. Ge. Situated learning in an educational technology course for pre-service teachers, Teaching and Teacher Education, 27(8): 1200-1212, 2011.

[26] M. Young. Assessment of situated learning using computer environments, Journal of Science Education and Technology, 4(1): 89-96, 1995

[27] R. Oliver, A. Herrington, J. Herrington, L. Sparrow. Using Situated Cognition in the Design of Interactive Multimedia-Based Learning Environments, The Japanese Educational Technology Annual Conference, November 1996, Kanazawa, Japan, 1996.

[28] S. Harley. Situated learning and classroom instruction, Educational Technology, 33(3): 46-51, 1993.

[29] S. Kemp. Situated learning: Optimizing experiential learning through god-given learning community, Christian Education Journal, 7(1): 118-143, 2010.

[30] T. C. Reeves. Evaluating Interactive Multimedia, In Multimedia for Learning: Development, Application, Evaluation, Educational Technology Publications, p. 97-112, ISBN: 978-0877782506, 1993.

[31] Y. C. Shih, M. T. Yang. A collaborative virtual environment for situated language learning using VEC3D, Educational Technology \& Society, 11(1): 56-68, 2008.

[32] Y. F. Yang. Engaging students in an online situated language learning environment, Computer Assisted Language Learning, 24(2): 181-198, 2011. 